\title{
Estimating the Intensity of Choice in a Dynamic Mutual Fund Allocation Decision
}

\author{
David Goldbaum* \\ University of Technology, Sydney \\ Bruce Mizrach \\ Rutgers University
}

Revised: February 2008

\begin{abstract}
:
The paper analyzes the intensity of choice in an agent based financial optimization problem. Mean-variance optimizing agents choose among mutual funds of similar styles but varying performance. We specify a model for the allocation of new funds, switching between funds, and withdrawals and obtain statistically significant estimates of the intensity of choice parameter. This estimate is also given economic interpretation through the underperformance of funds that use an active style. We find that agents with relative risk aversion of 2 will move $1 \%$ of their funds from active to passive for an extra 34 basis points of return.
\end{abstract}

JEL: G11.

Keywords: heterogenous agents; intensity of choice, mutual funds.

* Goldbaum is with the School of Finance and Economics, University of Technology, Sydney, Australia e-mail: david.goldbaum@uts.edu.au and Mizrach is with the Department of Economics, Rutgers University, New Brunswick, NJ 08901, email: mizrach@econ.rutgers.edu. We would like to thank three anonymous referees, the editor Cars Hommes, and participants at the 2005 meetings of the Society for Computational Economics for helpful comments. 


\section{Introduction}

Economists continue to explore alternatives to the representative agent paradigm. The interactions of dynamic heterogeneous populations provide explanations for economic behavior that is often difficult to explain using traditional models. The body of literature exploring heterogeneous agents models has grown to be quite extensive. Heterogeneity among agents has been used to model business cycles, financial market phenomena such as bubbles, excess volatility and clustering of returns, currency crises, and the flow of capital into and out of developing countries.

In the Agent Based Modeling approach, each individual in a population has a simulated interaction in an economic or financial setting. Evolution in strategy is typically governed by an adaptation mechanism such as a genetic algorithm. The approach offers an opportunity to observe the evolution of behavior in response to a changing non-equilibrium environment. The Santa Fe artificial stock market of Arthur et al (1997) and LeBaron (1999) is an example. The computational intensity of agent-based modelling can lead to limits on the size and complexity of the simulated environment. Further, since analysis is typically purely computational, interpreting simulation outcomes can be tricky due to the general lack of a formal model to impose structure.

An alternative strategy has been to sort individual agents into a small number of groups whose behavior is similar. Agents select which group to associate with for the period. Dynamics arise as the population gravitates between groups, typically in response to relative fitness that is itself dependent on the population. The resulting evaluation allows a combination of analytical and computational tools.

Discrete Choice Dynamics (DCD), introduced by Brock and Hommes (1997), models the evolution in population choice in the Adaptive Rational Equilibrium Dynamic (ARED). The framework is now a common tool for modeling the evolutionary process of a dynamic population. The DCD applies most naturally when a large population of individual agents choose among a small number of available discrete options. The heterogeneity of the population manifests as the population distributes among the choice set. The controlling parameter of the DCD model is the "intensity of choice" (IOC). The parameter determines the strength with which the population responds to perceived superiority of one of the choices. The value of the IOC parameter determines the nature of the population dynamics and thus the evolution of the model as a whole.

The DCD is utilized by Brock and LeBaron (1996) to match the correlation structure of stock return volatility and trading volume. Brock and Hommes (1998) is the first to explore how different 
values of the IOC parameter impact the dynamics of a financial market. The discrete choice faced by the traders is between alternative types of information to use as input in that period's portfolio decision process. Traders select between a costly rational price predictor and a free linear adaptive belief function (a trend chasing strategy). Increasing the IOC parameter increases the extremes to which the population shifts between the two information sources, causing complex dynamics that range from a stable unique fixed point, bifurcations, and limit cycles, to eventually produce chaotic behavior.

Extensions include Gaunersdorfer (2000) who allows agents to employ risk adjusted performance measures. In de Fontnouvelle (2000), traders are uncertain of the endogenously determined advantage of acquiring private information in a Grossman and Stiglitz (1980) type model. The traders choose between a costly rational forecast or naive adaptive model. Chiarella and He (2002) allows agents to be heterogenous in their tolerance for risk and in their estimates of conditional variance for the different trading strategies. Goldbaum (2003) allows the traders to choose between fundamental analysis and the use of a simple technical trading rule. DeGrauwe and Grimaldi (2005) employ a similar model in a foreign exchange market. Economic applications of the DCD include Chiarella and Khomin (1999) and Brock and de Fontnouvelle (2000). In both, agents select between a small number of methods to forecast inflation.

In all of the considered models, the IOC determines, as in the Brock and Hommes (1998), whether a model possesses a stable fixed point, cycles, or produces chaotic behavior. In application, the IOC parameter is set at the discretion of the modeler. Often it is a control parameter examined over a range of values to explore the dynamic behavior that a particular model is able to achieve.

To date, there have been only a small number of empirical estimates of the IOC. In each case the estimate of the IOC is not the objective, but a component of characterizing market behavior using a dynamic population model. Branch (2004) models inflation forecasts in which agents select between three strategies requiring varying degrees of effort or sophistication. He uses survey data in which households report an estimate of the inflation rate. The researcher does not directly observe which model is being employed by the individual, but the proportion of the market using each option in each period is inferred from the reported forecasts. The value of the IOC is determined by the population's responsiveness to recent performance measures of the prediction strategies. Similarly, Boswijk, Hommes, and Manzan (BHM, 2007) estimate the IOC as part of a model in which traders form predictions using either mean reverting or trend following 
beliefs for prices. Again, the actual choice by individual traders in the market is unobserved, but population proportions are inferred from the behavior of prices. The data used for the estimation is the same S\&P500 dividend and price series used by Shiller (1989) updated to extend to 2003. BHM's estimate of the IOC, however, is insignificantly different from zero. ${ }^{1}$

This paper contributes to the existing literature on the DCD by estimating the IOC and by putting an economic value on the implied resistance to change. We place the intensity of choice into a utility maximizing framework so that the IOC can be measured in a standard economic context. An added advantage of the portfolio choice setting is that we can also easily transform utility differences into dollar returns to further assess their reasonableness.

The finance literature has struggled to explain the dispersion of fund choices and even the dispersion within fund categories. Elton, Gruber and Busse (2004) conclude that because arbitrage is difficult, dominated products can prosper in the mutual fund industry. They claim that dispersion among commodity products like index funds is evidence of investor irrationality though. Hortaçsu and Syverson (2004) find that investors value heterogeneity but only a small portion of the return differences can be attributed to search costs. Our paper shows that the heterogenous agent framework may provide an alternative explanation.

Section 2 defines the intensity of choice. Section 3 describes the mutual fund allocation decision. Section 4 discusses data and parameters used to estimate the intensity of choice. Section 5 describes the estimation of the model and reports the results of the analysis. Section 6 concludes.

\section{Intensity of Choice}

The foundation for the ARED system is the randomized discrete choice framework of Manski and McFadden (1981). Consider an environment in which agents make a single selection from a set of $K$ discrete options. The agents estimate the relative benefits of each choice. In discrete choice studies, not all agents necessarily choose the option the model indicates to be the best choice for the individual. McFadden (1981) attributes the deviation in behavior to either unmodelled idiosyncratic components of the agents' utility function $U_{i}$ or to a component of randomness in individual preferences. Either explanation introduces a degree of randomness so that the individual agent's ranking of the options may differ from the modeler's. Each agent can be thought of as

\footnotetext{
${ }^{1}$ With the IOC parameter at zero, BHM's heterogeneous agent DCD model reduces to a linear model without strategy switching. Using a bootstrap $F$-test, BHM were able to strongly reject linearity in favor of the nonlinear heterogeneous agent DCD model.
} 
having a private estimate of the value of each of the options.

Consider a $K=2$ model in which agents are homogeneous in their modeled component of individual preferences. In the discrete choice model of Manski and McFadden (1981) agent $i$ has utility value for each option $k, U_{i, k}, k=0,1$ that is captured by the random realization of

$$
U_{i, k}=U_{k}+\sigma \varepsilon_{i, k}
$$

The idiosyncratic component $\sigma \varepsilon_{i}$, is i.i.d. with an Extreme Value distribution for $\varepsilon_{i}, E\left(\varepsilon_{i, k}\right)=$ $0, V\left(\varepsilon_{i, k}\right)=1$. The resulting probability individual $i$ selects option 1 is

$$
\operatorname{Pr}\left(x_{i}=1\right)=\frac{e^{\rho U_{1}}}{e^{\rho U_{1}}+e^{\rho U_{0}}} .
$$

The randomness in agent $i$ 's selection arises from idiosyncratic perception of the value of each option.

The IOC parameter, $\rho$, in (2) is an inverse function of $\sigma$ in (1). The lower is $\sigma$, and thus the greater is $\rho$, the greater is the proportion of agents that adopt the superior option. At the extreme, the model fully captures individual choice of a uniform population, in which case $\operatorname{Pr}\left(x_{i}=k\right)=1$ for $U_{k}>U_{-k}$, and $\operatorname{Pr}\left(x_{i}=k\right)=1 / 2$ if $U_{1}=U_{0}$. This result is produced in (2) by $\rho \longrightarrow \infty$. The greater $\sigma$, the weaker is the model at predicting an agent's choice. At this extreme, as $\sigma \longrightarrow \infty$, the model has no predictive ability and the probability associated with each choice is $1 / 2$. This is evident in (2) with $\rho=0$.

In a large population of $N$ agents, the law of large numbers ensures that for the proportion of the population selecting option $k, \lambda_{k} \longrightarrow \operatorname{Pr}\left(x_{i}=k\right)$ as $N \longrightarrow \infty$. The discrete choice framework ensures that the majority choice corresponds with the model's ranking of the two options. The heterogeneity of the population captured by $0 \leq \rho<\infty$ ensures that there is a tail of the population that selects the model's indicated lower ranked option. A larger $\rho$ represents a smaller $\sigma$ producing a tighter population distribution around the modeler's $U_{1}-U_{0}$ and thus a smaller tail of the population whose beliefs are in conflict with the model.

Brock and Hommes (1997) characterize the failure of the full population to embrace the higher ranked option as a manifestation of bounded rationality. The heterogeneous agent explanation of Manski and McFadden allows the possibility that for each agent $i, U_{i, 1}$ and $U_{i, 0}$ differ from $U_{1}$ and $U_{0}$ respectfully, allowing that agents are in fact behaving rationally given their idiosyncratic information or preferences.

In a dynamic system in which $U_{1, t}-U_{0, t}=f\left(\lambda_{t}\right)$ and $\lambda_{t}$ is set based on relative fitness consistent 
with (2), the existence and stability of a fixed point depends on $\rho$. Setting $\rho=0$ ensures a fixed point with $\lambda_{t}=1 / 2$. As $\rho$ increases, the system can become unstable, producing multiple equilibria or chaos. A large number of papers explore the range of dynamics produced by $\rho$ in different market environment.

We seek to clarify the interpretation of $\rho$ by embedding choice dynamics into a portfolio optimization problem. The next section describes the allocation problem and institutional environment.

\section{Mutual Fund Allocation Decision}

In making portfolio allocation decisions, investors seek to maximize their expected utility. Mutual funds have historically been the vehicle for achieving diversification at relatively low cost. Among funds, there is a related choice to make between active and passive investment strategies. With actively managed funds, investors hire managers to increase their returns within a given risk tolerance.

Recent literature has amply documented the underperformance of active mutual fund managers. $^{2}$ Beginning with the Vanguard funds in 1976, a growing pool of money has been managed passively, with portfolio weights tied to an index. By far the most popular of these is the Standard and Poor's 500 index, an index of large capitalization stocks, that represents approximately $85 \%$ of the total U.S. market capitalization. Mostly due to their lower expenses, these passive funds have on average produced higher returns than their actively managed counterparts.

We model the dynamics of the wealth allocated to active, $x_{A, t}$, and passive assets, $x_{P, t}$. As a new entrant into the investor's choice set, not only will passive funds attract a portion of the new funds, which we refer to as funds from cash, $z_{C \rightarrow P}$, but some investors will look to transfer funds out of active funds into passive funds, $z_{A \rightarrow P}$. The corresponding flows for the active assets are $z_{C \rightarrow A}$ and $z_{P \rightarrow A}$. Some funds will also leave the sector, with $z_{P \rightarrow C}$ the passive outflow, and $z_{A \rightarrow C}$ the active outflow. The inflow of wealth into both the active and passive funds represents both the distribution of new wealth and the redistribution of existing wealth from other asset types.

The transition equation for active assets consists of the organic return, $\left(1+r_{A, t}\right)$, the flows switched from passive funds, new flows from other sectors, less funds switched to passive assets and out of the sector,

$$
x_{A, t+1}=\left(1+r_{A, t}\right) x_{A, t}+\left(z_{P \rightarrow A, t}+z_{C \rightarrow A, t}\right)-\left(z_{A \rightarrow P, t}+z_{A \rightarrow C, t}\right) .
$$

$\overline{2}$ The most comprehensive reference remains the study by Carhart (1997). 
The corresponding expression for passive flow is

$$
x_{P, t+1}=\left(1+r_{P, t}\right) x_{P, t}+\left(z_{A \rightarrow P, t}+z_{C \rightarrow P, t}\right)-\left(z_{P \rightarrow A, t}+z_{P \rightarrow C, t}\right) .
$$

The portfolio allocation decision of the investors is reflected in the proportion of cash flowing into passive funds,

$$
\lambda_{t}=\frac{z_{C \rightarrow P, t}}{z_{C \rightarrow P, t}+z_{C \rightarrow A, t}} .
$$

The denominator, $z_{C \rightarrow P}+z_{C \rightarrow A}$, represents the flow of wealth into the asset universe being considered. This ratio of gross inflows constrains the population proportions to be in the $[0,1]$ interval. With a homogeneous population of mean-variance optimizers, all investors would allocate their cash to superior performing passively managed assets. The fact that actual flows do not reflect such one sided investing is a reflection of heterogeneity or bounded rationality in the population. The relative inflows, and thus $\lambda_{t}$, should be a reflection of $U_{P, t}-U_{A, t}$ and of the intensity of choice parameter, $\rho$.

The parameter $\lambda_{t}$ as defined in (5) reflects the discrete choice faced by investors of distributing new investment funds between two competing portfolios. We utilize cash inflows in our estimation because these funds face fewer impediments to reallocation. Fees and tax considerations are two of the most important barriers to adjustment that may keep a fully rational investor from her unconstrained optimum. It would be inappropriate to attribute deviations from the optimum due to these frictions to heterogeneity of beliefs, heterogeneous information, or bounded rationality, the traditional interpretations associated with finite IOC parameters.

Additionally, gross inflows, rather than net flows, are examined because relative inflow offers a pure reflection of investor preferences. Perceptions of performance, not size, determined how new funds are allocated by informed investors. Both size and performance determine the relative outflow of funds. ${ }^{3}$

The modeled binary decision is within a homogenous asset class of large capitalization stocks. The targeted choice between similar active and passive funds, and the implicit IOC revealed in the investors' decisions, will be largely unaffected by the investors' other portfolio allocation decisions.

Unfortunately, $z_{C \rightarrow P}$ and $z_{C \rightarrow A}$ are not directly observed. We only observe total inflows and total outflows for each type of fund. We include, in Table 1, Vanguard's Index 500 Securities and

\footnotetext{
${ }^{3}$ For example, if two similarly performing funds each attract $50 \%$ of the new funds and both lose $10 \%$ of their assets for liquidity reasons, but Fund A is twice as large as Fund B, then $66 \%$ of the withdrawn wealth will have come from Fund A with only $33 \%$ coming from Fund B. Net inflows incorrectly leave the impression that Fund B is more popular than Fund A.
} 
Exchange Commission (SEC) filing for illustration.

[Insert Table 1 Here]

In 1995, there were net purchases of $\$ 5.15$ billion in the Vanguard Index 500 fund. This was a combination of new cash allocations $z_{C \rightarrow P, t}$ and funds transferred from active funds, $z_{A \rightarrow P, t}$. In the same year, there were outflows to cash, $z_{P \rightarrow C, t}$, and transfers into active assets, $z_{P \rightarrow A, t}$ of $\$ 1.68$ billion. These numbers grow quite dramatically through the sample, peaking at $\$ 31.6$ billion of inflows in 1999 and $\$ 28.0$ billion in outflows in 2000. By the end of our sample in 2003, we return to a steadier inflow of $\$ 13.0$ billion and outflow of $\$ 10.3$ billion.

Let $y_{1, t}$ represent total inflow into active funds, $y_{1, t}=\left(z_{P \rightarrow A, t}+z_{C \rightarrow A, t}\right)$, and let $y_{2, t}$ represent total outflow from active, $y_{2, t}=\left(z_{A \rightarrow P, t}+z_{A \rightarrow C, t}\right)$. Denote $y_{3, t}=\left(z_{A \rightarrow P, t}+z_{C \rightarrow P, t}\right)$ and $y_{4, t}=$ $\left(z_{P \rightarrow A, t}+z_{P \rightarrow C, t}\right)$ as the corresponding entries for passive funds. Net inflows to the active sector, $y_{1, t}-y_{2, t}$, are negative from 2000 to 2003 . Net inflows to the active sector, $y_{3, t}-y_{4, t}$, are negative from 2000 to 2002 . We now parameterize each of these allocation decisions.

Extracting $z_{C \rightarrow P}$ and $z_{C \rightarrow A}$ from the observed $y_{1}$ through $y_{4}$ data series requires a pair of identifying assumptions. We chose a model with outflows in fixed proportion, $z_{A \rightarrow P}=w_{1} z_{A \rightarrow C}$ and $z_{P \rightarrow A}=w_{2} z_{P \rightarrow C}$, because it produced non-negative cash inflows over the widest range of parameters. ${ }^{4}$ This assumption implies the following dynamical system for active and passive inflows and outflows,

$$
\left[\begin{array}{l}
y_{1, t} \\
y_{2, t} \\
y_{3, t} \\
y_{4, t}
\end{array}\right]=\left[\begin{array}{cccc}
1 & 0 & 0 & w_{2} \\
0 & 0 & \left(1+w_{1}\right) & 0 \\
0 & 1 & w_{1} & 0 \\
0 & 0 & 0 & \left(1+w_{2}\right)
\end{array}\right]\left[\begin{array}{c}
z_{C \rightarrow A, t} \\
z_{C \rightarrow P, t} \\
z_{A \rightarrow C, t} \\
z_{P \rightarrow C, t}
\end{array}\right] .
$$

Our strategy is to first obtain estimates of the parameters $w_{1}, w_{2}$, and $\rho$ from the observables.

\footnotetext{
${ }^{4}$ We considered many other identifying assumptions and found two additional models consistent with our requirement that all fund flows be positive: (1) Fixed relative outflows: $z_{P \rightarrow C}=m_{1} z_{A \rightarrow C}$ and $z_{P \rightarrow A}=$ $m_{2} z_{A \rightarrow P}$; and (2) Outflows as a proportion of fund size: $z_{P \rightarrow C, t} / x_{P, t}=m_{1} z_{A \rightarrow C, t} / x_{A, t}, z_{P \rightarrow A, t} / x_{P, t}=$ $m_{2} z_{A \rightarrow P, t} / x_{A, t}$; Once we impose constraints on the $m^{\prime} s$ to maintain positive fund flows, the implied $z$ flows are quite similar across all the models. Both IOC estimates are significant at the $1 \%$ level and within one standard error of the estimates in Table 2.
} 
Imposing the constraints, an inversion of (6) yields,

$$
\left[\begin{array}{c}
z_{C \rightarrow A, t} \\
z_{C \rightarrow P, t} \\
z_{A \rightarrow C, t} \\
z_{P \rightarrow C, t} \\
z_{A \rightarrow P, t} \\
z_{P \rightarrow A, t}
\end{array}\right]=\left[\begin{array}{cccc}
1 & 0 & 0 & \frac{-w_{2}}{1+w_{2}} \\
0 & \frac{-w_{1}}{1+w_{1}} & 1 & 0 \\
0 & \frac{1}{1+w_{1}} & 0 & 0 \\
0 & 0 & 0 & \frac{1}{1+w_{2}} \\
0 & \frac{w_{1}}{1+w_{1}} & 0 & 0 \\
0 & 0 & 0 & \frac{w_{2}}{1+w_{2}}
\end{array}\right]\left[\begin{array}{l}
y_{1, t} \\
y_{2, t} \\
y_{3, t} \\
y_{4, t}
\end{array}\right] .
$$

We report on data collection and estimation of the dynamic model in the next section.

\section{Data}

\subsection{Fund universe}

To estimate the intensity of choice, it is desirable that the subjects be potentially heterogeneous in their estimation of relative performance between fund types, but homogeneous with regards to their preference for returns and risk. To this end, we look at a group of active and passive mutual funds that track closely the S\&P 500 index. Morningstar groups these funds as an equity style called "Large Cap Blend." 209 funds in the Morningstar Principia database have 10-year track records from 1994 to 2003. We have data on assets under management for all but 10 of the funds, and two funds merged, leaving a final sample of 198. The group is diverse, including load and no-load funds. There are 161 active funds, ranging in asset size from Fidelity Magellan (FMAGX) with $\$ 68.0$ billion to Black Rock Select Equity (PCESX) with only $\$ 1.9$ million. Among the 37 passive funds are the Vanguard S\&P 500 index (VFINX) with $\$ 71.9$ billion under management and the Black Rock Index Equity (PNESX) with $\$ 70.8$ million.

Many passive assets are also now invested in exchanged traded funds. The largest is the Standard and Poor's depository receipts, SPY. This fund increases from a $\$ 565$ million market capitalization at the end of 1994 to $\$ 44$ billion by the end of 2003 .

The underperformance of the actively managed funds is evident in our sample. No group of fund managers seems to display a consistent track record of stock picking, and the additional costs from trading, higher expenses and loads lead them to trail most index funds. In our 10-year sample, this is true with an average 10-year load adjusted performance of $9.70 \%$ versus $10.49 \%$ for the index funds. Over the 10 years, choosing the active funds will lead to a nearly $30 \%$ cumulative underperformance, or $\$ 2,997$ on a $\$ 10,000$ investment. 
The index funds display a surprising degree of heterogeneity, ${ }^{5}$ with mean 10-year returns ranging from $11.13 \%$ for the Vanguard Institutional Index (VINIX) to MainStay Equity Index A (MSCEX) at 10.12\%. The Vanguard S\&P 500 Index has a mean 10-year return of $10.99 \%$.

Even though the S\&P 500 index, the benchmark for all the funds in this group, is a passive index, it has been quite volatile, especially in the last three bear market years. The index funds have a standard deviation of $21.39 \%$ versus only $19.44 \%$ for the active funds. Using the average 3-month Treasury bill rate over the sample of $4.10 \%$, the passive funds have a higher Sharpe ratio, 0.3197 versus 0.2880 for the active funds. For VFINX, the Sharpe ratio is 0.3212 .

\subsection{Net and gross flows}

Based on the higher Sharpe ratio, many risk averse investors would prefer to hold the passive funds. In this class of funds though, the ratio of passively indexed to actively managed money is less than 1 to 5 at the beginning of our sample in 1994. With the passage of time, the higher returns and greater inflows raise the ratio.

\section{[Insert Figure 1 Here]}

Relative net inflows rise from $39 \%$ in 1994 to $99 \%$ in 2003. By the end of the sample, assets in the active funds have risen to $\$ 297.4$ billion from $\$ 110.4$ billion, but the index funds have risen from $\$ 21.0$ billion to $\$ 222.1$ billion. Over the 10-year period, the passive funds attract more than $90 \%$ of the net inflows. Our decision framework will try to explain this preference through the growing utility dominance of the passive funds and the intensity of choice.

As previously mentioned, we do not have sector wide data on gross inflows and outflows and must obtain this data at the individual fund level. We obtained SEC filings ${ }^{6}$ for the 5 largest funds in the active and passive categories. ${ }^{7}$ Based on 2003 assets, our 4 active funds represent $17.8 \%$ of total assets, and our 5 passive funds capture $83.37 \%$ of the total. We extrapolate the flows to the

5 See Elton, Gruber and Busse (2004).

6 The data are from Form N-CSRS and N-30D, the Certified Shareholder Reports, which can be downloaded from the SEC website.

${ }^{7}$ We ommitted Fidelity Magellan from our flow estimates for the active category. Although it was the largest fund in the group, it had a highly erratic pattern of flows not reflective of the sector. The four active funds are in order of 2003 assets: Fidelity Growth and Income; Fidelity Dividend Growth; Davis NY Venture A; and Legg Mason Value. The five passive funds are: Vanguard S\&P 500 Index; Standard and Poor's Depository Receipts, Vanguard Institutional Index; Vanguard Total Stock Market; Fidelity Spartan US Equity Index. We estimated (10) including Magellan, and this raised the estimated intensity of choice to 2.504 at $\gamma=2$. 
rest of the sector based on the relative size of the funds to form estimates of $\left(y_{1}, y_{2}\right)$ and $\left(y_{3}, y_{4}\right)$ for the entire sample.

\section{Specification and Estimation}

\subsection{Preferences}

We let $\lambda_{t}$ vary with the utility differences and the intensity of choice parameter $\rho$,

$$
\lambda_{t}(\rho)=\left(\tanh \left(\rho\left(U_{P, t}-U_{A, t}\right) / 2\right)+1\right) / 2 .
$$

We assumed constant relative risk aversion (CRRA) preferences,

$$
U=W^{1-\gamma} /(1-\gamma)
$$

varying $\gamma$ from log utility, $\gamma=1$, to $\gamma=4$. We then take a second order Taylor expansions around expected wealth, so that means and variances are sufficient statistics,

$$
U \approx U(E[W])-U^{\prime \prime}(E[W]) V[W]
$$

where $E[W]$ is expected wealth, $V[W]$ is the variance of wealth. ${ }^{8}$ We use rolling, capitalizationweighted sample means and variances up to time $t$ in our estimates.

\subsection{Estimation}

We find the values of $w_{1}, w_{2}$, and $\rho$ to minimize the mean squared error in the equation, derived from (5),

$$
z_{C \rightarrow P, t}-\lambda_{t}(\rho)\left(z_{C \rightarrow P, t}+z_{C \rightarrow A, t}\right)=0
$$

where $\lambda_{t}(\rho)$ is as defined in (8). Using (7), we then estimate using nonlinear least squares

$$
y_{3}=\psi_{1} y_{2}-\lambda_{t}(\rho) \psi_{1} y_{2}+\lambda_{t}(\rho)\left(y_{1}+y_{3}\right)-\lambda_{t}(\rho) \psi_{2} y_{4}
$$

where $\psi_{1}=w_{1} /\left(1+w_{1}\right)$ and $\psi_{2}=w_{2} /\left(1+w_{2}\right)$. The fixed parameters to be estimated ${ }^{9}$ are $\psi_{1}, \psi_{2}$, $\rho$, and a constant term $c$. Estimates for the three levels of risk aversion are reported in Table 2.

[Insert Table 2 Here]

The intensity of choice estimates using heteroscedasticity and autocorrelation consistent (HAC)

8 Gaunersdorfer (2000) also uses risk adjusted performance as a fitness measure.

${ }^{9}$ We imposed the constraints $w_{1} \geq 0$ and $0 \leq w_{2} \leq 0.96$ which are required to keep fund flows positive. These constraints were not binding in the estimation. 
standard errors are all statistically significant at the $1 \%$ level even with just 9 years of data. They range from 0.91 for the $\log$ to 6.53 at $\gamma=4$.

Switching between active and passive funds is well captured by the model. The finding of $\psi_{1}=1.0$ indicates that essentially $100 \%$ of the funds flowing from active funds to cash are then reinvested in the passive funds, while almost none of the funds exiting the passive funds, $\psi_{2}=0.002$, are transferred to active assets.

The model explains between $77 \%$ and $80 \%$ of fund flows. The best fit is from the case $\gamma=2$, with the fitted and actual data for passive fund inflows graphed in Figure 2.

\section{[Insert Figure 2 Here]}

While the passive funds are receiving nearly all net fund inflows, the active funds still hold a larger stock of assets. A forecast, using a constant and time trend, predicts that passive assets will not overtake active assets until 2041. Extrapolating from the average return differences and average 10 year inflows, the ARED estimates show a much earlier dominance. By 2021, a full twenty years earlier, the passive funds will hold more than $50 \%$ of assets in this mutual fund class.

\subsection{Comparative Statics}

We report results on the comparative statics of the model. We measure the change in expected return $\Delta E_{\lambda}[W]$ required to attract all inflows to the passive funds beyond the current $90 \%$. With $\log$ utility, 25.61 basis points are required to increase flows by $1 \%$. As the representative investor becomes more risk averse, it becomes harder to induce additional inflows because the active funds have a lower variance. 33.85 basis points are required in our best fit case with $\gamma=2$. At $\gamma=4$, it rises to 83.02 basis points.

To put these estimates in dollar terms, we assume an initial wealth of $\$ 10,000$. For an investor with assets at that level, an extra $\$ 65.86$ per year in the log case would attract $1 \%$ more inflows. In the most risk averse case, $\$ 218.56$ would be needed to attract $1 \%$ more inflows.

To assess the reasonableness of these estimates, we compare them to a variety of fund metrics. The estimates are close to the 100.56 basis point cross sectional performance dispersion of the passive funds. The estimates also seem reasonable compared to the 160 basis points transactions $\operatorname{costs}^{10}$ on the average equity mutual fund.

${ }_{10}$ See John C. Bogle, "Mutual Fund Directors: The Dog that Didn't Bark," Speech on January 28, 2001. 


\section{Conclusion}

The literature on heterogenous agents has been adding useful insights to many areas of economics. A key step forward to wider application, we believe, is to better understand the intensity of choice parameter. This seems true for papers that calibrate or estimate models involving discrete choice dynamics.

We have used agent based modeling and discrete choice dynamics to understand investor choices among mutual funds. At the beginning of our 10 year sample, actively managed funds dominate the landscape, with more than 5 dollars of assets for every 1 in the passive funds. Over time though, the actively managed funds under-perform on both an absolute and risk-adjusted basis. Consistent with our framework, the passive funds attract a growing share of net inflows each year. The discrete choice dynamics model explains up $80 \%$ of the variation in fund flows.

Our principal contribution has been to estimate a statistically significant estimate of the intensity of choice parameter. While this is a free parameter in estimation, it has an economic interpretation in the context of our decision problem. Furthermore, by choosing a financial optimization problem, we get estimates that can be measured in dollars rather than utility units. While the intensity parameter varies with the degree of risk aversion, the range of dollar costs is quite reasonable. In our leading case, with relative risk aversion of $\gamma=2$, a change of 34 basis points in returns can increase fund inflows by $1 \%$. These estimates are in line with performance and fund fee variation among the choices currently available to investors.

We speculate that embedding discrete choice dynamics in a utility maximizing framework may provide dividends in other areas of economics and finance. 


\section{References}

Arthur, W.B., Holland, J., LeBaron, B., Palmer, R., Tayler, P., 1997. Asset pricing under endogenous expectations in an artificial stock market. In: Arthur, W.B., S. Durlauf, and D. Lane (eds.), The Economy as an Evolving Complex System II. Addison-Wesley, Reading, MA, 15-44.

Boswijk, H.P., Hommes, C.H., Manzan, S., 2007. Behavioral heterogeneity in stock prices. Journal of Economic Dynamics and Control 31, 1938-1970 .

Branch, W. A., 2004. The theory of rationally heterogeneous expectations: evidence from survey data on inflation expectations. Economic Journal 114, 592-621.

Brock, W.A. and de Fontnouvelle, P., 2000. Expectations diversity in monetary economics. Journal of Economic Dynamics and Control 24, 725-759.

Brock, W. A. and Hommes, C., 1997. A rational route to randomness. Econometrica 65, 1059-95.

Brock, W. A. and Hommes, C., 1998. Heterogenous beliefs and routes to chaos in a simple asset pricing model. Journal of Economic Dynamics and Control 22, 1235-74.

Brock, W.A. and LeBaron, B.D., 1996. A dynamic structural model for stock return volatility and trading volume. The Review of Economics and Statistics 78, 94-110.

Carhart, M., 1997. On persistence in mutual fund performance. Journal of Finance 52, 57-82.

Chiarella, C., He, X., 2002. Heterogeneous Beliefs, Risk and Learning in a Simple Asset Pricing Model. Computational Economics 19, 95-132.

Chiarella, C. and Khomin, P., 1999. Adaptive evolving expectations in models of monetary dynamics: The fundamentalists forward looking. Annals of Operations Research 89, 21-34.

de Fontnouvelle, P., 2000. Information dynamics in financial markets. Macroeconomic Dynamics 4, 139-169.

DeGrauwe, P. and Grimaldi, M., 2006. Exchange rate puzzles: A tale of switching attractors. European Economic Review 50, 1-33.

Elton, E., M. Gruber, and Busse, J., 2004. Are investors rational? choices among index funds. Journal of Finance 59, 261-88.

Gaunersdorfer, A., 2000. Endogenous fluctuations in a simple asset pricing model with heterogenous beliefs. Journal of Economic Dynamics and Control 24, 799-831.

Goldbaum, D., 2003. Profitable technical trading rules as a source of price instability. Quantitative Finance 3, 220-229.

Grossman, S.J., Stiglitz, J.E., 1980. On the impossibility of informationally efficient markets. The American Economic Review 70, 393-408.

Hortaçsu, A. and Syverson, C., 2004. Product differentiation, search costs, and competition in the mutual fund industry: a case study of S\&P 500 index funds. Quarterly Journal of Economics 119, 403-56.

Lasselle, L., Svizzero, S. and Tisdell, C., 2005. Heterogenous expectations, dynamics, and stability of markets. Macroeconomic Dynamics 9, 630-650.

LeBaron, B., Arthur, W.B., Palmer, R., 1999. The time series properties of an artificial stock market. Journal of Economic Dynamics and Control, 23, 1487-1516.

Manski, C.F., and McFadden, D., 1981. Structural Analysis of Discrete Data with Econometric 
Applications. MIT Press, Cambridge, MA.

McFadden D., 1981. Econometric models of probabilistic choice. In: Manski, C.F., McFadden D. (Eds.), Structural Analysis of Discrete Data with Econometric Applications. MIT Press, Cambridge, MA. 
Table 1

Annual Flows for Vanguard Index 500 Fund

$\begin{array}{lrr}\text { Share transactions }(\$ \mathrm{mn}) & \mathbf{1 9 9 5} & \mathbf{2 0 0 3}\end{array}$

\begin{tabular}{lll}
\hline (1) Proceeds from sales of shares & $5,153.18$ & $13,026.69$
\end{tabular}

(2) Cost of shares redeemed $\quad 1,682.11 \quad 10,323.65$

The table reports fund inflows and outflows in millions of dollars from the SEC certified shareholder form N-CSR for the Vanguard S\&P 500 index fund (VFINX). 
Table 2

Intensity of Choice in the Dynamic Model

\begin{tabular}{crrrrrr}
\hline Model & $\rho$ & $\psi_{1}$ & $\psi_{2}$ & $c$ & $\bar{R}^{2}$ & $\Delta E_{\lambda}[W]$ \\
\hline \hline$\gamma=1$ & 0.9095 & 1.0000 & 0.0025 & $2,878.10$ & 0.7899 & $0.2561 \%$ \\
& $(3.28)$ & $(3.42)$ & $(0.00)$ & $(579.87)$ & & \\
$\gamma=2$ & 1.9308 & 1.0000 & 0.0025 & $2,887.75$ & 0.8010 & $0.3385 \%$ \\
& $(10.36)$ & $(2.90)$ & $(0.00)$ & $(10.68)$ & & \\
$\gamma=4$ & 6.5308 & 1.0000 & 0.0014 & $2,648.93$ & 0.7672 & $0.8302 \%$ \\
& $(51.78)$ & $(12.79)$ & $(0.00)$ & $(17.95)$ & &
\end{tabular}

We vary, across the three estimates, the risk aversion parameter $\gamma$ from 1 to $4 . \rho$ is the estimate of the intensity of choice. $\psi_{1}$ and $\psi_{2}$ are the outflow proportions into passive and active assets. $c$ is a constant term. $t$-ratios are in parentheses. $\Delta E_{\lambda}[W]$ is the change in expected return required to achieve a $1 \%$ increase in inflows to the passive funds. 
Figure 1

\section{Ratio of Net Inflows to Passive Funds}

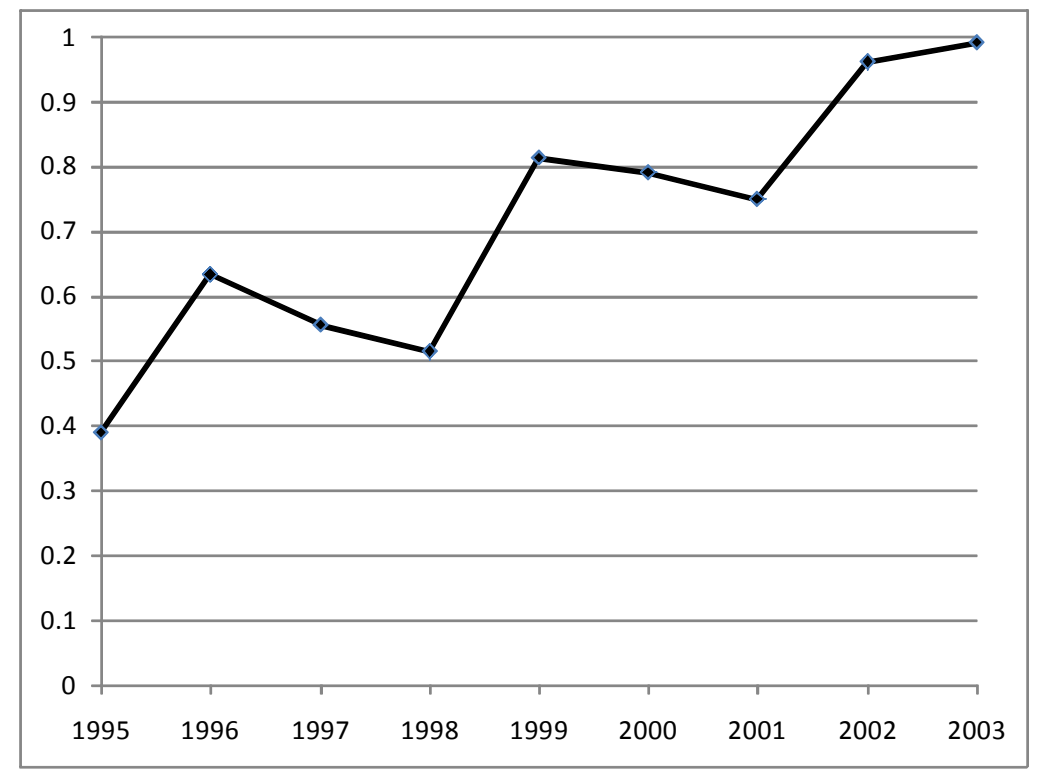

The figure graphs the proportion of net fund inflows going into passive versus active funds. It tracks the growing appeal of passive assets during our sample period from 1995-2003. 
Figure 2

Total Fund Inflows for Passive Funds $y_{3, t}$ : CRRA $\gamma=2$

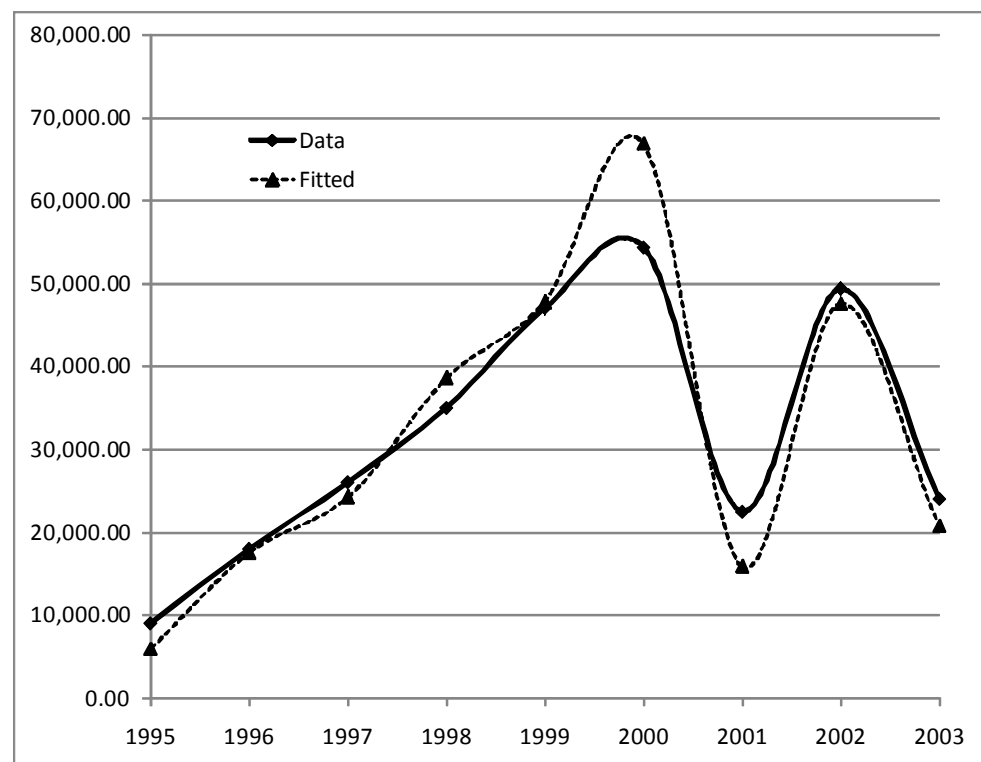

The figure plots data and fitted values for estimates from (10) of total fund inflows, in millions of dollars, into passive funds. 